\title{
Budi Clinic: Actualization and Habituation of Mapalus Cultural Value
}

\author{
Darmawan Edi Winoto* \\ History Education Department \\ Faculty of Social Sciences \\ Universitas Negeri Manado \\ Tondano, Nort Sulawesi, Indonesia \\ darmawanediwinoto@unima.ac.id
}

\author{
Ridwan \\ Electrical Engineering Education Department \\ Faculty of Engineering \\ Universitas Negeri Manado \\ Tondano, Nort Sulawesi, Indonesia \\ ridwan@unima.ac.id
}

\begin{abstract}
Preliminary study results showed that students lacked a sense of solidarity, cooperation, or help and a low cultural awareness attitude. Need solution to overcome the problem is with Budi clinic. This article aims to describe the implementation, actualization and habituation of the cultural values of Mapalus to the students through the activities of Budi clinic. The method used is qualitative with 40 respondents. Data analysis uses coding and categorisation, as well as interactive analyses that include data collection, data reduction, and verification to find common patterns. Data validation uses method Trianggulation. Results showed that there are two activities in Budi Clinic namely survey activities and provision of facilities and infrastructure that support the the cultural value of Mapalus.
\end{abstract}

Keywords: Actualization, Budi clinic, Cultural Awareness

\section{INTRODUCTION}

Preliminary study results showed that students lacked a sense of solidarity, cooperation, or help and a low cultural awareness attitude. Potential conflicts may occur at any time. Conflicts that occur can be various forms, can be inner conflicts (psychological) students (intrapersonal), conflicts between students (interpersonal) because of differences exist, conflicts between individuals in groups (intra-group) caused by unfamiliarity, and last can be a conflict among members of the group (inter-group) because of competition or disputes. This attitude cannot be left alone. Individuals who cannot cooperate with others at one time he or she will become a stranger. Although culture please help has existed in the culture and identity of the Minahasa people called Mapalus or famous slogan for example bites all Basair and Si tou timou tumou tou. These cultures are true if applied to students, awareness of culture, please help, in cooperation will inspire and motivation so that students do please help.

Solution overcome the problem that is with Budi clinic. Budi Clinic assists students in destroying the value of Mapalus culture. The activities in Budi clinic encourage students to cooperate, Gotongroyong, and encourage knowledgeable students and have the cultural attitude of Mapalus. Mapalus is a form of the traditional royong of the ancestor of the Minahasan ancestors who is a system of procedures, methods or techniques of cooperation for the mutual interest of each member in turn [1]. Mapalus appears on the basis of the realization of togetherness, limitations on the ability of both thinking, working, and so forth. So, this mapalus is a form of togetherness that is always in the Junjung by the Minahasa people in scheduling togetherness among the community.

\section{METHOD}

Design research uses a qualitative approach. The informant in this study contained 40 respondents. The survey instrument used in this research is interviews and Quisioner which contains 4 main components. On the first component want to see the student capability and performance aspects. In this aspect used a closed statement that is useful to see the student's perception of cooperation gotongroyong. Second, the use of social aspect in interacting with peers. Third, paedagogical and technical aspects in the actualization of the value of Mapalus culture. Lastly, habituation of Mapalus value in the activity of Budi clinic.

Data analysis uses coding and categorisation of each word or sentence in the Quisioner that is relevant to the indicator of each of these research topics. Data analysis also uses interactive analytics which include data collection, data reduction, and verification to find common patterns. Data validation using method trianggulation by checking by interview with corresponding respondent to ensure data is written correctly according to reality.

\section{RESULT AND DISCUSSION}

\section{A. Activity Survey}

Survey activities are conducted in order to determine the level of cultural awareness of students in the historical Education Department of 
Universitas Negeri Manado. Surveys are conducted independently without relying on others. This Survey is also oriented to produce an efficient questionnaire (in terms of cost) of quality, effective (achieving objectives) and encourages knowledge and performance oriented students [1]. Survey also supports the existence of organization effectiveness. Effectiveness is the degree in which the organization detractors its objectives, while its effectiveness is the suitability of the results achieved by the Organization with the objectives or objectives set. The most important element of effectiveness is its dicita-citakan fundamental purpose. Preliminary surveys are effective for identifying student culture awareness that is useful for universities. With known cultural awareness of students, it will be easy to do the appropriate treatment to produce resources that will be useful for the organization and society as a broad.

Performance oriented students with the treatment of students to be able to behave and behave according to cultural values. The expected cultural value is Mapalus which is a local culture in Minahasa. This culture of Mapalus prioritizes cooperation, mutual assistance, help each other. These cultural values need to be implanted and highly esteemed by the students [2]. These cultural values are useful for student life both at university and after they graduate and live in the community [3]. When the values of Mapalus are firmly embedded in students, students can be an example for the people around wherever they are. The obstacles faced in this activity are students understand cultural awareness[4]. The solution gives an understanding of cultural awareness, and explains the purpose of the poll given.

The ethics of Pubik in the form of polite attitude when consulting with the mentor, the head of department and the responsibility of the college, if executed properly, will get support and assistance from the mentor and the occurrence of good communication so that the purpose of the consultation can be carried out well. This polite attitude in addition to being an ethical attitude towards leadership, also relates to respect to older people who are the norm of modesty in society. Courtesy is the life rule of the Association of Human beings. Manners can be demonstrated by not doing the deeds that can offend others, the leadership of the work unit. For example, say rude, like to lie, do not hear advice and direction of leadership. Thus we are required to be able to do fun of others, in a good and praiseworthy manner as with the performance of the satisfactory leadership. Sowan (requesting permission) to the leader when going on campus activities is a small example, but it is an attitude we appreciate and respect the leadership and leadership also feel appreciated by the subordinates.
Quality commitment, in carrying out surveys as possible to adhere to effective and efficient principles and quality. Quality commitment is implemented so that existing resources can be made to the fullest and use a very effective time so that the objectives of this stage is achieved well. Effective in achieving the desired objectives namely to know the student culture consciousness. Efficient in terms of cost, by using questionnaires with the help of Google form, making and distribution is much cheaper. Efficient also in terms of time. How to adopt a poll of existing research by being modified will shorten the creation time. Charging Kuesioiner online, in scoring is much faster. Compare it to how many students there are about 50 people, then share it, and then have to be counted manually. Manual way like this is less effective and takes a short time.

Public service, with the assessment done fairly without discriminate one student with the other, the assessment is more objective. Objective assessments are also supported with questionnaires allowing to assess students objectively. Justice is the first virtue in social institutions. Without the principle of justice, a social institution will collapse easily. In the assessment, for example, without the principle of justice, many students will be harmed and eventually feel disappointed because he felt the victim of discrimination, arbitrariness and the rights to gain justice in public. Worse yet, the students lost respect and trust. If this is the case, it could be that the lecturer will not hear the word nor its actions. Each lecturer gave the task, students can do the original so. Perception of students to lecturers is unfair to give value/scoring has been attached to students. The stereotypes of lecturers in college students have been less than good, then whatever the lecturers do will be negative in the eyes of students. Therefore, the principle of justice especially giving value to students must be enforced. Otherwise, the above risk may be accepted by the lecturer. Restoring student confidence is very difficult to do. Do not rate the student by weight, and waive the principle of justice.

\section{B. Provision of Facilities and Infrastructure}

Anti-corruption, realized through independent indicators in the provision of facilities and infrastructure in terms of funding using personal funds for the purchase of equipment so as not to rely on university funds that if this is not applied will interfere with the financial stability of the university. In addition, it is a self-initiative to provide the tools and materials needed. The leader never forced the will to intervene the banner creation Budi. Banner Budi is freely determined by us, planning the process as it is, the use of existing materials. Self-reliance is an active and participatory learning to develop oneself that is not 
tied to others. Self-reliance requires motivation, persistence, seriousness, discipline, responsibility, willingness, and curiosity to develop ourselves where we can develop ourselves [5]. Motivate yourself to what extent we can do something. We ourselves that determine the direction of the banner Budi later like what. Simple in terms of materials but useful to support banner creation. Buy the tools and materials that are needed for the creation of the banner Bob. The tools and materials are purchased in accordance with the wishes and capabilities, but still prioritize the principle of cheap, effective and efficient.

Quality commitment, realized through independent indicators in this case is the use of equipment so that it is easier and simpler. It also raises the element of persistence to work on it. Whenever possible, use the tools and materials available in the market to make it easier to set up to our liking. Mandiri here can be interpreted as a desire to realize the tools and materials available for the creation of banners. Independently without command and ultimatum from the leadership, but to place the leader as a place of discussion not as the ruling party or ruled. So that all of the necessary equipment decisions, its design is like what it depends we are making it. Without any coercion from the leadership that the creation of the banner Budi must be the desired leader.

Public service, effective and efficient. The use of the tools and materials banner Budi done effectively and efficiently. The tools and materials used are cheap and many found in the market but can be utilized to the fullest. This is done so that the existing materials can be utilized properly. If not done effectively and efficiently, the material is not enough to create a banner. Worse will increase the cost of purchasing the equipment and materials needed. There is also an element of creativity in it so that the tools and materials creation of the banner Budi can easily be realized [6].

\section{Making Budi Clinic}

This activity supports the strengthening of the organizational value of Team work. Cooperation is sometimes an activity that is still much avoided by some people in the work environment. But there are many advantages that we can receive from teamwork in the team, both for ourselves and for the organization. Not only does it offer the opportunity to thrive, but teamwork also means we can make work feel lighter and easier. When working in teams, we will work towards the same goal together. All work processes will be lighter and more efficient.

One of the biggest advantages we will receive after our teamwork is that we and the Organization will get inspiration and new ideas from a team discussion. When we exchange ideas about making Budi clinic with leaders, associates, and students there is a scope of creativity that is much more and wider than when we think of the idea alone [7]. Many ideas are expressed, such as the need for Budi clinic to be forwarded in the Student Association program in the History Education department. And the program will not be the way if the students of the majors do not follow up. So cooperation is indispensable.

In an environment where teamwork is solid and effective, all team members feel confident in raising ideas. Responsibilities of the employer can be held together in the team and solve the problems in the team. Lecturers give trust to leaders to lead direction of course. There is a strong inner bond that between members does not feel awkward to express his idea.

Communication is key to the success of a goal. Activities involving teamwork require good communication, both oral and written [8]. Working on a team helps us develop communication skills with others. Through teamwork, we can freely conduct open discussions so that we get adequate information relating to the topic of discussion. So organizational objectives can be achieved in teamwork.

Budi Clinic assists in the cultivation of cooperation among students. In order for students to play an active role in succeeding their goals and universities where he studied. Budi Clinic aims to allow students to have a cultural awareness to cooperate. Working together is important, because it can bring students and lecturers and leaders from different backgrounds but can collaborate together. Each member has the role of an agent that encourages the creation of organizational objectives.

Civil Servant managements are particularly integrity. Integrity means a concept of consistency whether in action, word, or deed. The principles that are believed, the values of life that have been committed are continuously. The most important is the commitment to be continuous. Integrity in carrying out activities by requesting permission to superiors, using good and correct language, polite, and clear in acting need to be done continuously and become habituation in the workplace [9]. If this is done, then it can be said it has integrity. By having an attitude of integrity, he has a belief in the eyes of people around, reliable and undisputed. Integrity relates to the attitude of responsibility, honesty. What is said to be the same as what is done. It is heavy to be said to be a person of integrity. However, by starting small things by asking for permission and consulting every activity to the leader, it becomes a personally-integrity can be realized. Consultation with leaders is not only an attitude of our integrity as subordinates to the leader, but also as the attitude of our appreciation as a subordinate to the leadership. Attitude 
appreciates leadership as a form of loyal attitude to the leader and important so that we are also appreciated as subordinates.

Anti-corruption is realized through hard work, discipline, self-reliant and simple indicators. Budi Clinic was completed in accordance with the previously planned targets through hard work and cooperation between all the parties in the university. Hard work means daring to do the job more enterprising, appreciating the time. Without any hard work, any activity or wishes will not be carried out including making and organizing Budi clinic. Budi Clinic is only a gesture when it has no hard work attitude. Therefore, to accomplish something it needs to work hard. Hard work means also rewarding time. A hard-working person will not waste any time. Leisure time is sometimes used to arrange the location of Budi clinic.

Discipline is also closely related to hard work and rewarding time. A disciplined person will do something regularly. Do work with high commitment and responsibility to resolve. Budi Clinic is completed thanks to the attitude of discipline, independence and always motivate yourself that Budi Clinic can be realized well when we are sure. Motivation and self-discipline start from planning Budi clinic in a mature basis until realizing it. Realizing Budi Clinic is a priority agenda for approximately one month. In addition, seriousness, diligence, and consistency become key in self-discipline. Budi Clinic is an all-in-one.

Simple means the attitude of humility. Humility accepts what happens and does not want anything excessively. Desires are on the self just want Budi clinic materialize. Budi Clinic which is designed according to self-ability, without the need to replicate the clinic has others, the most important thing is to do according to what we want. Budi Clinic would like what it is, his style, the program, the concept of all of us who design and manifest [10].

\section{CONCLUSION}

Budi Clinic supports the actualization and habituation of Mapalus cultural values. These values are reflected in two activities, namely the initial survey activities and in the provision of facilities and infrastructure activities. The first activity is a survey conducted with the aim to know the level of cultural awareness, organization effectiveness and performance oriented for students. Performance oriented students with the treatment of students to be able to behave and behave according to cultural values. The expected cultural value is Mapalus which is a local culture in Minahasa. This culture of Mapalus prioritizes cooperation, mutual assistance, help each other. These cultural values need to be implanted and highly esteemed by the students. When the values of Mapalus are firmly embedded in students, students can be an example for the people around wherever they are.

Secondly, the activities of making the clinic Budi support the value of team work. Budi Clinic assists in the cultivation of cooperation among students. Budi Clinic aims to allow students to have a cultural awareness to cooperate. Working together is important, because it can bring students and lecturers and leaders from different backgrounds but can collaborate together. Each member has the role of an agent that encourages the creation of organizational objectives. Budi Clinic was completed in accordance with the previously planned targets through hard work and cooperation between all the parties in the university. Budi Clinic is completed thanks to the attitude of discipline, independence and always motivate yourself that Budi Clinic can be realized well when we are sure. Motivation and self-discipline starts from planning Budi clinic maturely to realize.

\section{AKNOWLEDGMENT}

Thank you to the all Research Team for Our Cooperation and to the student from Universitas Negeri Manado and for Rector for supporting the research.

\section{REFERENCES}

[1] T. Pangalila, J. Mantiri, and M. Umar, 'The Role of Mapalus Local Wisdom in Building the Tolerant Attitudes of the Tomohon City Community', in 2nd International Conference on Social Science (ICSS 2019), 2019, vol. 363, no. Icss, pp. 711-714.

[2] T. M. Liu and S. K. Chang, 'Changes in local knowledge and its impacts on ecological resources management: The case of flyingfish culture of the Tao in Taiwan', Mar. Policy, vol. 103, no. September 2018, pp. 74-83, 2019.

[3] E. Belfiore, 'Whose cultural value? Representation, power and creative industries', Int. J. Cult. Policy, vol. 26, no. 3, pp. 383-397, 2020.

[4] M. H. Lin and H. C. Hsu, 'Effects of a cultural competence education programme on clinical nurses: A randomised controlled trial', Nurse Educ. Today, vol. 88, no. 261, 2020.

[5] A. Ghermandi, V. Camacho-Valdez, and H. Trejo-Espinosa, 'Social media-based analysis of cultural ecosystem services and heritage tourism in a coastal region of Mexico', Tour. Manag., vol. 77, no. September 2019, p. 104002, 2020.

[6] P. R. Schulman, 'Organizational structure and safety culture: Conceptual and practical challenges', Saf. Sci., vol. 126, no. January, p. 104669, 2020.

[7] E. Ucar, 'Local creative culture and corporate innovation', J. Bus. Res., vol. 91, no. May, pp. 60-70, 2018

[8] J. Rius-Ulldemolins and R. Klein, 'Does cultural policy matter? Political orientations, cultural 
management models, and the results of public cultural action in Barcelona and Valencia', Local Gov. Stud., vol. 00, no. 00, pp. 1-25, 2020.

[9] A. Caputo, O. B. Ayoko, N. Amoo, and C. Menke, 'The relationship between cultural values, cultural intelligence and negotiation styles', J. Bus. Res., vol. 99, no. September 2018, pp. 23-36, 2019.

[10] L. Sharman, N., Wallace, C.A., Jespersen, 'Terminology and the understanding of culture, climate, and behaviorual change-Impact of organizational and human factors on food safety management', Trend Food Sci. Technol., vol. 96, pp. 13-20, 2020.

[11] Z. Chen, B. King, and W. Suntikul, 'Co-creation of value for cultural festivals: behind the scenes in Macau', Tour. Recreat. Res., vol. 0, no. 0, pp. $1-15,2020$. 